\title{
Clinical and pathological features of squamous cell carcinoma of the lip
}

\author{
Aydan KILIÇARSLAN ${ }^{1}$, Hayriye T. DOĞAN ${ }^{1}$
}

${ }^{1}$ Department of Pathology, Medical School, Ankara Yıldırım Beyazıt University, Ankara, Turkey.

\section{SUMMARY}

The aim of this study was to evaluate the patients with squamous cell carcinoma (SCC) of the lip in terms of age, sex, tumor localization, tumor size, histopathological subtype, lymph node metastasis, and recurrence rates.

Forty patients with lip SCC were included in the study. A large majority of the patients were within the age range of 61-79 years (50\%). SCC was located in the lower lip in 35 (87.5\%) patients. The average diameter of the tumor was $2.15 \mathrm{~cm}$ (range $0.4-7 \mathrm{~cm}$ ). The most common histopathological subtypes were well differentiated $(n=15,37.5 \%)$ and microinvasive SCC $(n=12,30 \%)$. All patients underwent tumor excision with safe surgical margins. In six patients (15\%) with local recurrence after total excision, two SCCS were localized on the right side of the lower lip, two on the left side of the lower lip, and two in the middle of the lower lip. Four of them were well-differentiated SCC, one was poorly differentiated SCC, and one was moderately differentiated SCC.

Cervical lymph node metastasis was detected in two (33.3\%) patients with recurrence. SCCS located on the lower lip were more aggressive than basal cell carcinomas, which were quite common in the head and neck regions. Despite total excision, patients should be followed up closely in terms of recurrence and metastasis. Tumor localization, size, and submandibular lymph nodes should be taken into account in addition to the histopathological subtype of tumor at the time of diagnosis.

Key words: Lip neoplasm, recurrence, squamous cell carcinoma

\section{INTRODUCTION}

Lip cancers are one of the most common cancers in the head and neck regions and constitute $25 \%-30 \%$ of all oral cavity cancers (1). Lip cancer is located on the lower lip in $87.2 \%-90 \%$ of the patients (2,3). Squamous cell carcinoma (SCC) constitute 95\% of the lip cancers (4-6). Lower lip SCCs are most commonly seen in Caucasian male smokers. They are often seen in the sixth decade of life. Etiology is multifactorial, but prolonged sun exposure has a major role. Histological changes, such as leukoplakia, hyperkeratosis, and actinic cheilitis, are also observed in adjacent tissues. Besides, sun rays, pipe and cigarette smoking, bad dental hygiene, chronic alcoholism, and immunosuppression also contribute to tumor development. The standard treatment for lip cancer is surgical excision and reconstruction (7). Surgical excision should be done carefully and the excisional material and its boundaries should be subjected to histopathological examination in three dimensions to obtain the highest cure rate and the smallest defect size (8). A probability exists of recurrence and regional metastasis in 5\%-15\% of all lower lip SCCs (9). Distant metastasis is expected in 15\% of these patients. Histopathologically, tumor thickness is a determining factor for regional metastasis. Therefore, it is an important criterion in treatment planning (10). In the present study, 40 patients with lip SCC were reported. The purpose of the study was to evaluate these patients in terms of epidemiology, histopathology, and recurrence.

\section{MATERIALS AND METHODS}

This study was conducted retrospectively at the Pathology Department of Atatürk Training and Research Hospital, Ankara Yıldırım Beyazıt University Faculty of Medicine. It evaluated 40 patients diagnosed with SCC on the lips during a period of 10 years between 2008 and 2018. A punch biopsy was performed in all patients with an SCC prediagnosis according to the

Correspondence:

Aydan KILIÇARSLAN

Ankara Yıldırım Beyazıt Üniversitesi Tıp Fakültesi Pataloji Bölümü, Ankara, Türkiye.

e-mail: dr.kilicaydan@gmail.com 
clinical findings, and a final diagnosis was made. Excisional borders were determined according to clinical findings, tumor size, and localization. Small lesions with clear borders were excised with a 5-mm safety margin, whereas large lesions with indefinite borders were excised with a 10-mm safety margin. The clinicopathological data (age, sex, clinical stage, the presence of recurrence, and recurrence date) were retrieved from the pathology reports and patient files. All slides prepared from the surgical specimens of the patients were obtained from the pathology archive and examined again according to the 2017 World Health Organization Classification of Head and Neck Tumors (11). The diagnosis of the patients was reevaluated in terms of tumor subtypes presence of dysplasia surrounding the tumor, tumor size, muscle and nerve invasions, and metastatic lymph nodes. In addition, the presence of inflammation was graded as not mild and moderate-to-severe.

SPSS 22.0 (IL, USA) was used for statistical analysis. The MannWhitney $U$ test and chi-square test were used for continuous and categorical variables, respectively. A P value $<0.05$ was considered as statistically significant.

\section{RESULTS}

This study retrospectively evaluated 40 patients with lip SCC. Of these, 28 (70\%) were male and 12 (30\%) were female. The incidence of SCC was significantly higher in men than in women $(P<0.05)$. The mean age of the patients was $68.7 \pm 13.8$ years. The highest prevalence was observed between the ages of 61-79 years (50\%) (Fig. 1).

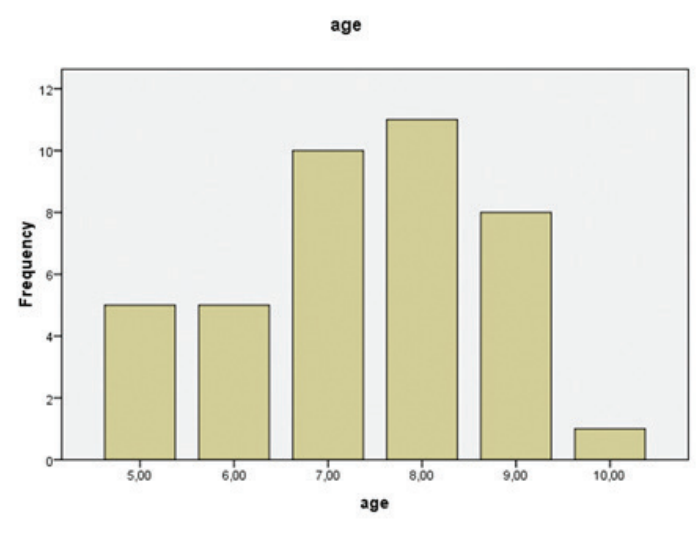

FIGURE 1: Distribution of the patients according to ages.

In terms of tumor localization, 35 (87.5\%) tumors were localized on the lower lip and 5 (12.5\%) were localized on the upper lip. Of the 35 tumors with lower lip involvement, 13 (32.5\%) were in the middle region, 11 (27.5\%) in the right region, and 11 (27.5\%) in the left region. The mean tumor size was $1.6 \mathrm{~cm}$. The diameter of the lesion was less than $10 \mathrm{~cm}$ in 11 patients (27.5\%), 10-30 mm in $23(57.5 \%)$ patients, and more than $30 \mathrm{~mm}$ in $6(15 \%)$ patients. Tumor diameter was between 10 and $30 \mathrm{~mm}$ in most patients ( $P$ $<0.05)$.

Of 13 tumors located in the middle region of the lower lip, 5 (38.4\%) were well-differentiated SCC (Table 1). Seven (63.6\%) of the 11 tumors located on the right side of the lower lip were welldifferentiated SCC. Four (36.3\%) of the 11 tumors located on the

TABLE 1: Tumor localization and SCC histologic types in lip.

\begin{tabular}{|c|c|c|c|c|c|c|c|}
\hline \multirow{2}{*}{$\begin{array}{l}\text { SCC } \\
\text { histological } \\
\text { type }\end{array}$} & \multicolumn{6}{|c|}{ Tumor localization in lip } & \multirow{2}{*}{ Total } \\
\hline & $\begin{array}{c}\text { Middle of the } \\
\text { lower lip }\end{array}$ & $\begin{array}{l}\text { Right side of } \\
\text { the lower lip }\end{array}$ & $\begin{array}{l}\text { Left side of the } \\
\text { lower lip }\end{array}$ & $\begin{array}{c}\text { Middle of the } \\
\text { upper lip }\end{array}$ & $\begin{array}{l}\text { Right side of } \\
\text { the upper lip }\end{array}$ & $\begin{array}{l}\text { Left side of } \\
\text { the upper lip }\end{array}$ & \\
\hline Acantholytic & $1(7.7 \%)$ & $0(0 \%)$ & $0(0 \%)$ & $0(0 \%)$ & $1(50.0 \%)$ & $1(50.0 \%)$ & $3(7.5 \%)$ \\
\hline Poorly differentiated & $0(0 \%)$ & $0(0 \%)$ & $1(9.1 \%)$ & $0(0 \%)$ & $0(0 \%)$ & $0(0 \%)$ & $1(2.5 \%)$ \\
\hline Spindle cell & $1(7.7 \%)$ & $0(0 \%)$ & $0(0 \%)$ & $0(0 \%)$ & $0(0 \%)$ & $0(0 \%)$ & $1(2.5 \%)$ \\
\hline Well differentiated & $5(38.4 \%)$ & $7(63.6 \%)$ & $2(18.2 \%)$ & $1(100.0 \%)$ & $0(0 \%)$ & $0(0 \%)$ & $15(37.5 \%)$ \\
\hline $\begin{array}{l}\text { Microinvasive, well } \\
\text { differentiated }\end{array}$ & $4(30.7 \%)$ & $2(18.2 \%)$ & $4(36.3 \%)$ & $0(0 \%)$ & $1(50.0 \%)$ & $1(50.0 \%)$ & $12(30 \%)$ \\
\hline $\begin{array}{l}\text { Moderately } \\
\text { differentiated }\end{array}$ & $2(15.4 \%)$ & $2(18.2 \%)$ & $3(27.3 \%)$ & $0(0 \%)$ & $0(0 \%)$ & $0(0 \%)$ & $7(17.5 \%)$ \\
\hline Basoloid & $0(0 \%)$ & $0(0 \%)$ & $1(9.1 \%)$ & $0(0 \%)$ & $0(0 \%)$ & $0(0 \%)$ & $1(2.5 \%)$ \\
\hline Total & $13(100.0 \%)$ & $11(100.0 \%)$ & $11(100.0 \%)$ & $1(100.0 \%)$ & $2(100.0 \%)$ & $2(100.0 \%)$ & 40 (100.0\%) \\
\hline
\end{tabular}




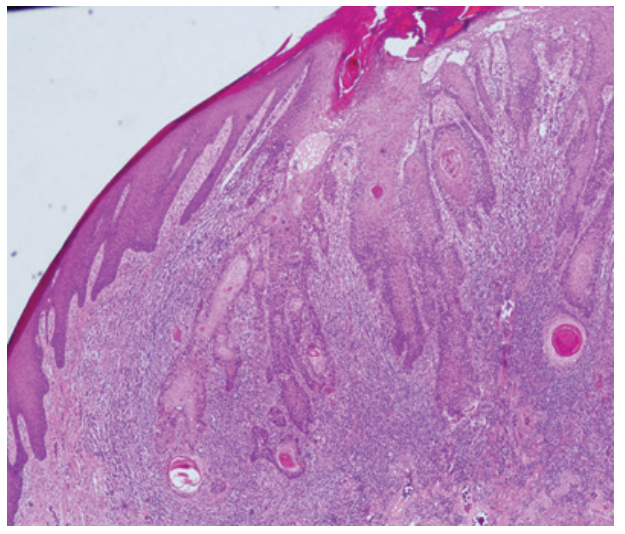

FIGURE 2: Well-differentiated SCC with dense inflammation (H\&E x40).

left side of the lower lip were microinvasive well-differentiated SCC (Fig. 2). Two (40\%) of the five tumors located on the upper lip were acantholytic SCC, two (40\%) were microinvasive SCC, and one was well-differentiated SCC.

The mean follow-up duration was $32 \pm 8.6$ months. Recurrence was observed in six (15\%) patients. The subtypes of recurrent SCC cases were well-differentiated SCC in four cases, poorly differentiated SCC in one patient (Fig. 3), and moderately differentiated SCC in one patient.

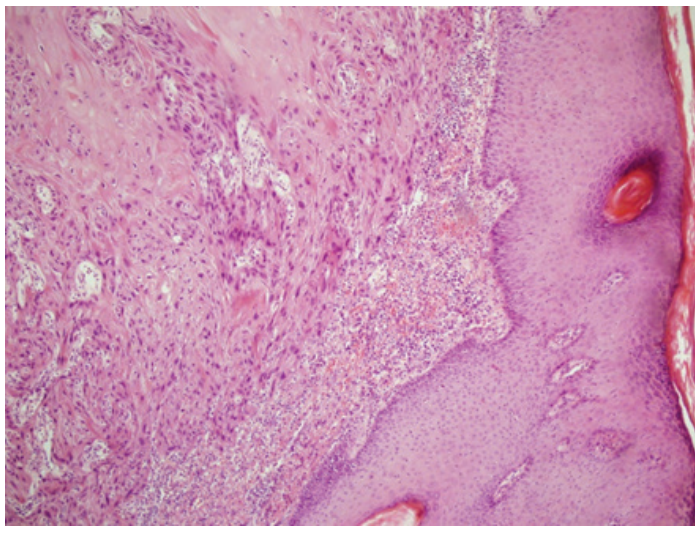

FIGURE 3: Poorly differentiated SCC with moderate inflammation (H\&E x100).
No statistically significant difference $(P>0.05)$ was found between patients with and without recurrence in terms of the presence of inflammation, presence of dysplasia surrounding the tumor, and nerve and muscle invasion (Table 2).

A large majority of patients $(n=32,61.5 \%)$ had moderate-tosevere inflammation. In five of the six patients with recurrence (83.3\%), moderate-to-severe inflammation was observed around the tumor. Nerve invasion was observed in two (5\%) patients, with no recurrence. Muscle invasion was detected in 10 patients (25\%).

\begin{tabular}{|c|c|c|c|c|}
\hline & & \multicolumn{2}{|c|}{ Tumor recurrence } & \multirow[t]{2}{*}{ Total } \\
\hline & & Positive & Negative & \\
\hline \multirow[t]{3}{*}{ Peritumoral inflammation } & Positive & $5(83.3 \%)$ & $27(79.4 \%)$ & $32(76.2 \%)$ \\
\hline & Negative & $1(16.7 \%)$ & $7(20.6 \%)$ & $8(19.0 \%)$ \\
\hline & Total & $6(100.0 \%)$ & $34(100.0 \%)$ & $42(100.0 \%)$ \\
\hline \multirow[t]{3}{*}{ Muscle invasion } & Positive & $1(16.7 \%)$ & $9(26.5 \%)$ & $10(23.8 \%)$ \\
\hline & Negative & $5(83.3 \%)$ & $25(73.5 \%)$ & $30(71.4 \%)$ \\
\hline & Total & $6(100.0 \%)$ & $34(100.0 \%)$ & $42(100.0 \%)$ \\
\hline \multirow[t]{3}{*}{ Perineural invasion } & Positive & $0(0 \%)$ & $2(5.9 \%)$ & $2(4.8 \%)$ \\
\hline & Negative & $6(100.0 \%)$ & $32(94.1 \%)$ & 38 (90.5\%) \\
\hline & Total & $6(100.0 \%)$ & $34(100.0 \%)$ & $42(100.0 \%)$ \\
\hline \multirow{3}{*}{$\begin{array}{l}\text { Presence of dysplasia } \\
\text { surrounding the tumor }\end{array}$} & Positive & $1(16.7 \%)$ & $6(17.6 \%)$ & $7(16.7 \%)$ \\
\hline & Negative & $5(83.3 \%)$ & $28(82.4 \%)$ & $33(78.6 \%)$ \\
\hline & Total & $6(100.0)$ & $34(100.0)$ & $42(100.0)$ \\
\hline
\end{tabular}


Local recurrence occurred in the patient (2.5\%) who had muscle invasion. At the time of diagnosis, metastatic lymphadenopathy was detected in three patients. Local recurrence was observed in two of these three patients. The mean tumor diameter was 3.3 $\mathrm{cm}$ in three patients with lymph node metastasis. In addition, the mean tumor diameter in patients with recurrence was $1.9 \mathrm{~cm}$.

\section{DISCUSSION}

Lip cancer is the most common cancer among oral cavity tumors. The most common malignant tumor on the lips is SCC (12). Furthermore, this region receives more sun exposure, and it is the most frequently affected area in smokers. The mortality of lower lip cancers has decreased consistently in the last 30-40 years. The current survival rates are more than $90 \%(3,13)$. As this region is highly visible, early diagnosis enables a cure rate of $90 \%-100 \%$ (14). Lip SCC is seen most frequently in the seventh decade (13). However, most of the patients in this study were older and in the age range of $70-80$ years ( $n=11,27.5 \%$ ). No statistically significant difference was detected between age groups. The frequency of lower lip SCC was higher in males (7). In the present study, the incidence was statistically significantly higher in males than in females. In accordance with the literature, the lesions were frequently located in the middle region of the lower lip in this study (3). This is where the sun rays reach most steeply; also this region comes into contact with cigarettes frequently.

Histopathologically, 28 patients (70\%) had well-differentiated lip SCCs (grades 1 and 2) in this study. Only one (2.5\%) patient had poorly differentiated SCC (grade 4). In accordance with the literature, the most frequent type was well-differentiated tumors in this study $(2,15)$. According to the TNM classification, the staging of primary lesion is made according to its size. Lesions smaller than $2 \mathrm{~cm}$ are classified as T1, lesions $2-4 \mathrm{~cm}$ as $\mathrm{T2}$, and lesions more than $4 \mathrm{~cm}$ as T3 (16). Most of the tumors in this study were T1 tumors $(n=34,85 \%)$.

The primary goal of the treatment of lip SCCs is surgical excision of the tumor, which is the most efficient method in terms of safety and benefit. The reconstruction of the defect should then be performed to reach an aesthetically and functionally acceptable outcome (1722). Recurrence rates after primary excision are reported as 7.5\%$11 \%(1,2)$. Recurrence is closely related to tumor size (more than $1 \mathrm{~cm}$ ), differentiation (poorly differentiated), and the presence of deep dermis and fat tissue invasion $(23,24)$. The recurrence rate in this study was also 15\%. The average of tumor diameter in patients with recurrence was $1.9 \mathrm{~cm}$. Four of the patients with recurrence (66.6\%) had T2 tumors, and their diameters were larger than 2 $\mathrm{cm}$. The study did not show a relationship between muscle and nerve invasion and recurrence due to small sample size. Also, no relationship was shown between recurrence and the presence of dysplasia surrounding the tumor. However, the presence of significant inflammation around the tumor was slightly higher in patients with recurrence $(n=5,83.3 \%)$. Larger case series may display the more significant relationship between muscle-nerve invasion and presence of significant inflammation around the tumor and recurrence.

The most important prognostic factor in the lower lip SSCs is the presence of regional metastatic lymph nodes. In recent years, various prognostic models and scoring systems have been used to determine the risk of regional lymph node metastasis. These factors include tumor localization, invasion depth, tumor size, tumor growth pattern, keratinization grade, nuclear polymorphism, tumor surrounding lymphocytic response, mitosis number, invasion pattern, lymphovascular invasion, and perineural invasion. In the present study, lymph node metastasis was found in three patients; it was located on the right side of the lower lip with severe inflammation around the tumor in two of these patients. Most studies concluded that tumor thickness was an important prognostic factor in subclinical and clinical metastasis formation. It is well known that the tissue samples shrink 20\%-30\% after the fixation process. Therefore, the most appropriate information about tumor thickness and invasion depth can be obtained with frozen sections (25). If the tumor thickness is $5 \mathrm{~mm}$ or more, the risk of regional lymph node metastasis is increased (26). The mean of tumor diameters in patients with lymph node metastases was higher than the mean of diameters in all patients $(2.5 \mathrm{~cm}$ vs $1.6 \mathrm{~cm})$.

The approach to regional lymph nodes in lower lip cancers is controversial. Cervical lymph node dissection is not necessary for T1 tumors (3). In the present case series, three patients with lymph node metastasis had tumor diameters of $2.1,2.5$, and $6.5 \mathrm{~cm}$. None of these had a T1 tumor.

In conclusion, the present case series showed that the histopathologic subtypes of lower lip SCC cases were mostly well differentiated and microinvasive well differentiated, whereas 
acanthotic type was found most frequently in patients with upper lip SCC. The probability of lymph node metastasis and local recurrence increased in patients with a tumor diameter greater than $2 \mathrm{~cm}$. The clinical significance of histopathological prognostic factors for lip SCC can be more clearly demonstrated in studies with larger case series.

\section{REFERENCES}

1. Zitsch RP. Carcinoma of the Lip. Otolaryngol Clin North Am 1993;26:265-277

2. McCombe D, MacGill K, Ainsline J, Beresford J, MatthewsJ. Squamous cell carcinoma of the lip: a retrospective review of the Peter MacCallum Cancer Institute experience 1979-88. Aust N Z J Surg. 2000 May;70(5):358-61.

3. Babington S1, Veness MJ, Cakir B, Gebski VJ, Morgan GJ. Squamous cell carcinoma of the lip: is there a role for adjuvant radiotherapy in improving local control following incomplete or inadequate excision? ANZ J Surg. 2003 Aug;73(8):621-5.

4. Anvar BA, Evans BC, Evans GR. Lip reconstruction. Plast Reconstr Surg. 2007;120:57e-64e.

5. Larson DL. Tumors of the lips, oral cavity, and oropharynx, in Mathes SJ (ed): Plastic Surgery (ed 2, Vol V). Philadelphia, PA, Saunders Elsevier, 2006, pp 159-187.

6. Sargeran K, Murtomaa H, Sahavi SM, et al. Malignant oral tumors in Iran: ten-year analysis on patient and tumor characteristics of 1042 patients in Tehran. J Craniofac Surg 2006;17:1230-1233.

7. Hasson O. Squamous cell carcinoma of the lower lip. J Oral Maxillofac Surg 2008;66:1259-1262.

8. Moehrle $M$, Breuninger $H$, Rocken M. A confusing world: what to call histology of three-dimensional tumour margins? J Eur Acad Dermatol Venereol 2007;21:591-595.

9. Baker SR, Krause CJ. Carcinoma of the lip. Laryngoscope 1980;90:19-27

10. Morselli P, Masciotra L, Pinto V, Zollino I, Brunelli G, Carinci F. Clinical parameters in T1N0M0 lower lip squamous cell carcinoma. J Craniofac Surg. 2007;18:1079-82.

11. El-Naggar AK, Chan JKC, Grandis JR, Takata T, Slootweg PJ. WHO Classification of Head and Neck Tumours. 4th Edition, 2017 Lyon, p 133, 2017.

12. Sykes AJ, Allan E, Irwin C. Squamous cell carcinoma of the lip: The role of electron treatment. Clin Oncol (R Coll Radiol) 1996;8:384.
13. Vukadinovic $M$, Jezdic $Z$, Petrovic $M$, Medenica LM, Lens $M$. Surgical management of squamous cell carcinoma of the lip: analysis of a 10-year experience in 223 patients. J Oral Maxillofac Surg 2007;65(4):675-9.

14. Otterburn DM, Saadeh PB. Head and neck cancer and salivary gland tumors, in Thorne $\mathrm{CH}$ (ed): Grabb and Smith's Plastic Surgery (ed 7). Philadelphia, PA, Lippincott Williams \& Wilkins, pp 327-341, 2014.

15. Bilkay U, Kerem H, Ozek C, Gundogan H, Guner U, Gurler T, Akin Y. Management of lower lip cancer: a retrospective analysis of 118 patients and review of the literature. Ann Plast Surg 2003;50(1):4350.

16. Luce EA. WHO Reconstruction of the lower lip. Clin Plast Surg 1995;22:109-21.

17. Karapandzic M. Reconstruction of lip defects by local arterial flaps. Br J Plast Surg 1974;27:93.

18. McGregor IA. Reconstruction of the lower lip. Br J Plast Surg 1983;36:40.

19. Nakajima T, Yoshimura $Y$, Kami T. Reconstruction of the lower lip with a fan-shaped flap based on the facial artery. Br J Plast Surg 37:52, 1984

20. Neto MS, Castilho HT, Ferreira LM, et al: Utilization of the depressor anguli oris musculocutaneous flap for lip reconstruction. Ann Plast Surg 44:23, 2000.

21. Papadopoulos $\mathrm{O}$, Konofaos $\mathrm{P}$, Tsantoulas Z, et al: Lip defects due to tumorexcision: Apropos of 899 cases. Oral Oncol 2007;43:204.

22. Demirseren ME, Afandiyev $\mathrm{K}$, Ceran C. Reconstruction of the perioral and perinasal defects with facial artery perforator flaps. J Plast Reconstr Aesthet Surg 2009;62:1616.

23. Roth JJ, Granick MS. Squamous cell and adnexal carcinomas of the skin. Clin Plast Surg. 1997; 24:687-703.

24. de Visscher JG, Gooris PJ, Vermey A, Roodenburg JL. Surgical margins for resection of squamous cell carcinoma of the lower lip. Int J Oral Maxillofac Surg 2002; 31:154-7.

25. Ribeiro NF, Godden DR, Wilson GE, Butterworth DM, Woodwards RT. Do frozen sections help achieve adequate surgical margins in the resection of oral carcinoma? Int J Oral Maxillofac Surg 2003; 32:152-8.

26. Kane SV, Gupta M, Kakade AC, D' Cruz A. Depth of invasion is the most significant histological predictor of subclinical cervical lymph node metastasis in early squamous carcinomas of the oral cavity. Eur J Surg Oncol 2006; 32:795-803. 